\title{
Phase Transitions in Oxides Studied by Perturbed Angular Correlation Spectroscopy
}

\author{
Michael Uhrmacher and Klaus-Peter Lieb \\ II. Physikalisches Institut, Bunsenstr. 7 - 9, Universität Göttingen, D-37073 Göttingen \\ Reprint requests to Dr. M. U.; E-mail: uhrmacher@physik2.uni-goettingen.de
}

Z. Naturforsch. 55 a, 90-104 (2000); received August 26, 1999

Presented at the XVth International Symposium on Nuclear Quadrupole Interactions, Leipzig, Germany, July 25 - 30, 1999.

\begin{abstract}
Radioactive atoms located on cation sites in oxide matrices can be used to monitor phase transitions by measuring the electric or magnetic hyperfine interactions by means of Perturbed Angular Correlations spectroscopy. The article illustrates three types of phase transitions studied with ${ }^{111}$ In tracers and their daughter nuclei ${ }^{111} \mathrm{Cd}$, namely magnetic, structural and REDOX phase transitions in binary and ternary polycrystalline or single-crystalline oxides. In this context, we also discuss the question of identifying the probes' lattice site(s), the scaling of the Electric Field Gradients in oxides, the influence of the (impurity) probes themselves on the phase transitions, and the occurrence and mechanisms of dynamic interactions. Recent results on ${ }^{111}$ In in pure and Li-doped $\mathrm{In}_{2} \mathrm{~S}_{3}$ will also be presented.
\end{abstract}

Key words: Phase Transitions; Oxides; Perturbed Angular Correlations; ${ }^{111}$ In; Point Charge Model.

\section{Introduction}

"A phase transition occurs when there is a singularity in the free energy or one of its derivatives" [1]. The diversity of phase transitions in oxides spans from antiferromagnetic and ferrimagnetic phase transitions, where the sublattice magnetization is the order parameter, to structural phase transitions (atomic displacements) and ferroelectric phase transitions (electric polarization) [2, 3]. Hyperfine interaction methods such as Mössbauer effect, Perturbed $\gamma$-ray Angular Correlations (PAC), Nuclear Magnetic or Quadrupole Resonance (NMR, NQR) and Myon Spin Resonance $(\mu \mathrm{SR})$ are particularly well suited to monitor local magnetic and electric fields and phase transitions associated with them. The present article reports on several types of phase transitions in binary and ternary oxides studied via PAC spectroscopy employing implanted radioactive ${ }^{111} \mathrm{In},{ }^{11 \mathrm{~m}} \mathrm{Cd}$ or ${ }^{111} \mathrm{Ag}$ tracers which all feed the $245 \mathrm{keV}$ isomeric state in ${ }^{111} \mathrm{Cd}[4]$.

Some general remarks concerning the use of PAC for studying the hyperfine interactions in oxides and the relevant definitions of the PAC parameters are the content of Section 2. Magnetic phase transitions in binary oxides are discussed in Section 3. In Sect. 4 struc- tural phase transitions, mainly in perovskite oxides, are reviewed and the scaling of Electric Field Gradients (EFGs) in different classes of oxides is discussed. A few examples of chemical phase transitions are presented in Sect. 5 which also addresses to the role of dynamic hyperfine interactions. Surveys on previous results for ${ }^{111}$ In-PAC spectroscopy in binary oxides have been given in a number of articles [5 - 9].

\section{Methods: Instrumentation and Analysis}

Besides the Mössbauer effect, PAC spectroscopy using radioactive ${ }^{111}$ In tracers is probably the most common hyperfine interaction method using unstable nuclei. This is due to several favorable conditions of these tracers: ${ }^{111}$ In decays via electron capture with the convenient halflife of $T_{1 / 2}=2.83 \mathrm{~d}$ to ${ }^{111} \mathrm{Cd}$ [4]. The decay feeds a two-step $\gamma$-cascade involving well resolved $\gamma$-radiations of 171 and $245 \mathrm{keV}$ and the hyperfine-sensitive $245 \mathrm{keV} \mathrm{5/2}{ }^{+}$ state, which has a long halflife ( $85 \mathrm{~ns}$ ), a precisely known magnetic moment $\left(\mu=-0.3062 \pm 0.0010 \mu_{\mathrm{N}}\right)$ and a large quadrupole moment $(Q=0.83 \pm 13 \mathrm{~b})$. As in Mössbauer spectroscopy, the benefits of PAC [10] lie in its high local sensitivity, which gives access to structures on an atomic scale. As long as the hyper- 
Table I. Components of a PAC laboratorium designed for the study of phase transitions.

\begin{tabular}{clllcclll}
\hline PAC set-up & Detectors & Shape & Angles & horiz., vertical & Turbo-pump & $T_{\min }(\mathrm{K})$ & $T_{\max }(\mathrm{K})$ & Specials \\
\hline 1 & $4 \mathrm{NaI}$ & cylindr. & $90^{\circ}$, fixed & $\mathrm{h}$ & yes & 10 & 850 & $\mathrm{Cryo}$ \\
2 & $4 \mathrm{NaI}$ & cylindr. & $90^{\circ}$, fixed & $\mathrm{h}$ & no & $\mathrm{R} . \mathrm{T}$. & 1350 & $\mathrm{CO} / \mathrm{CO} 2$ \\
3 & $4 \mathrm{NaI}$ & cylindr. & $90^{\circ}$, fixed & $\mathrm{h}$ & yes & $10 / 250$ & 850 & $\mathrm{Cryo} / \mathrm{Peltier}$ \\
4 & $4 \mathrm{BaF}_{2}$ & conical & $90^{\circ}$, fixed & $\mathrm{v} / \mathrm{h}$ & yes & $1.5 / 80$ & 450 & mobile \\
5 & $4 \mathrm{BaF}_{2}$ & cylindr. & variable & $\mathrm{h}$ & no & R. T. & R. T. & goniometer \\
\hline
\end{tabular}

fine interaction is constant during the observation time, PAC is able to resolve different (static) probe surroundings. The method has been extended to dynamic processes on the ns time scale [11 - 16]. PAC is able to distinguish between magnetic hyperfine fields, EFGs and superpositions of both. Moreover, it provides information about the orientation of internal fields relative to crystallographic axes. In comparison with Mössbauer spectroscopy, PAC is more favorable at higher temperatures since it does not depend on a Debye-Waller factor. A further advantage is the small number of radioactive tracer atoms necessary (some $10^{12}$ ) which, in general, do not influence the macroscopic properties of the matrix.

The main limitations of PAC derive from

1. the small number of appropriate nuclear probe nuclei available;

2. the necessity to introduce the radioactivity into the sample to be studied;

3. the need to calibrate the observed hyperfine fields; and

4. modifications which the (generally impurity) probe atoms may exert onto the local environment, either due to the chemical nature or the electric activity of the probe atoms or, in the case of implantation, radiation damage. For studying phase transitions, the possible changes of the local environment by the probes have to be checked as shown in Sect. 3 with the local reliese of frustration in $\mathrm{CuFeO}_{2}$ and in Sect. 4 at the spin-Peierls transition in $\mathrm{CuGeO}_{3}$.

The theory and methodology of PAC have been reviewed in several articles $[4,17,18]$. At the Göttingen laboratory, ${ }^{111}$ In can be either ion-implanted by means of the implanter IONAS [19], diffused into the sample or deposited via evaporation as thin and even submono layers when used in thin film analysis [20]. We have five 4-detector PAC apparatus available, equipped with either $4 \mathrm{~cm}$ long, $4 \mathrm{~cm}$ in diameter $\mathrm{NaI}(T l)$ or conical or cylindrical $\mathrm{BaF}_{2}$ scintillators. The temperature range accessible runs from about $10 \mathrm{~K}$ (closed-cycle helium cryostat; high vacuum chamber) to about $1400 \mathrm{~K}$. Here, a chamber of low $\gamma$ ray absorption can be operated either under a protective gas atmosphere or with a $\mathrm{CO} / \mathrm{CO}_{2}$ gas mixture to adjust the oxygen activity. For the $\mathrm{BaF}_{2}$ detector setup, Bartos et al. [21] developed a fast-fast electronic module, which includes the single channel analyzers, linear amplifiers, and pole-zero timing circuits for all four channels. Hence, this apparatus is small enough to be easily transportable to other facilities such as ISOLDE/CERN or to a liquid-He cryostate [22]. Table I summarizes the features of these instruments.

As usual, the perturbation function for a $90^{\circ}$ detector geometry is expressed as

$$
R(t)=A_{22}^{\mathrm{eff}} G_{2}(t)=2 \frac{N(t, \pi)-N(t, \pi / 2)}{N(t, \pi)+2 N(t, \pi / 2)},
$$

where $A_{22}^{\text {eff }}$ denotes the effective angular correlation coefficient of the unperturbed $\gamma \gamma$ cascade in ${ }^{111} \mathrm{Cd}$ and $N(t, \theta)$ the perturbed $\gamma \gamma$ coincidence rate between detectors separated by the angle $\theta=\pi$ and $\pi / 2$, respectively. In the case of a purely magnetic interaction, the Larmor frequency $\omega_{\mathrm{L}}$ is related to the hyperfine field $B_{\mathrm{hf}}$ via $\omega_{\mathrm{L}}=\mu_{\mathrm{N}} g B_{\mathrm{hf}} / \hbar$ and is obtained from

$$
G_{2}(t)=\sum_{n=0}^{2} S_{n} \cos \left(n \omega_{\mathrm{L}} t\right) \exp (-n \delta t) d\left(\omega_{\mathrm{L}} ; \tau_{\mathrm{R}}\right) .
$$

This expression assumes a unique site having a Lorentzian distribution of Larmor frequencies around the centre value $\omega_{\mathrm{L}}$ with width $\delta$, and a finite time resolution $\tau_{\mathrm{R}}$ of the PAC apparatus contained in the function $d\left(\omega_{\mathrm{L}} ; \tau_{\mathrm{R}}\right)$. The coefficients $S_{n}$ depend on the single- or poly-crystalline form of the sample. The extension to several sites is straightforward. The corresponding expression for a static electric quadrupole interaction is

$$
\begin{gathered}
G_{2}(t)=\sum_{n=0}^{3} s_{2 n}(\eta) \cos \left[g_{n}(\eta) \nu_{\mathrm{Q}} t\right] \exp \left[-g_{n}(\eta) \delta t\right] \\
\cdot d\left(g_{n}(\eta) \nu_{\mathrm{Q}} ; \tau_{\mathrm{R}}\right),
\end{gathered}
$$



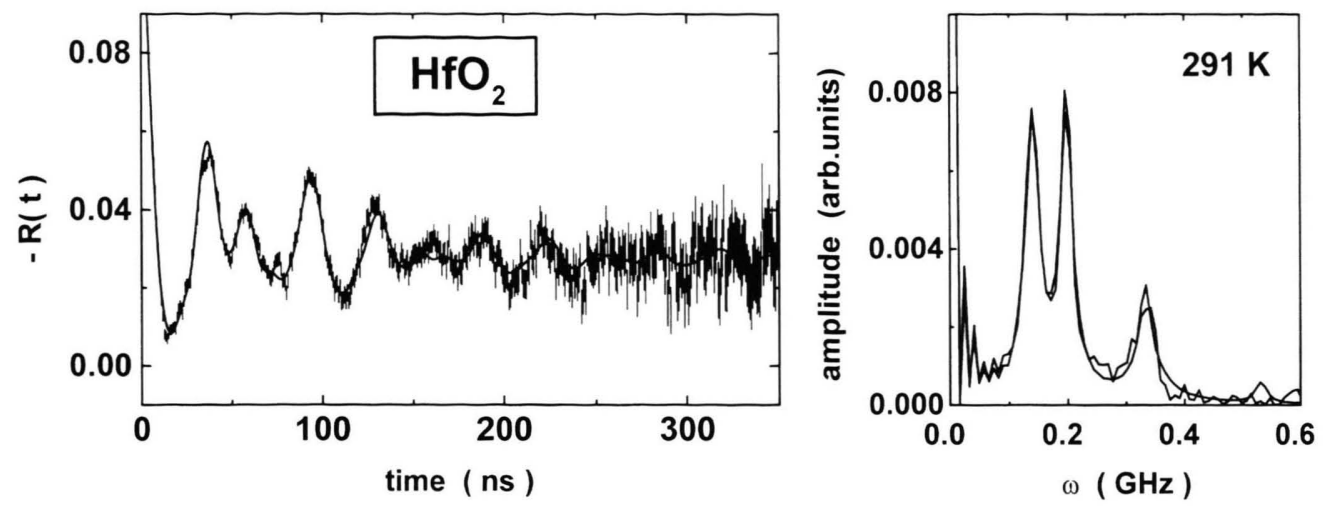

Fig. 1. PAC spectrum (left) and Fourier transform (right) taken at the measuring temperature $T_{\mathrm{m}}=291 \mathrm{~K}$ after ${ }^{111} \mathrm{In}$ implantation in $\mathrm{HfO}_{2}$ [32]. The measured EFG is attributed to ${ }^{111} \mathrm{Cd}$ on substitutional, defect-free cation sites.

where the quadrupole coupling constant $\nu_{\mathrm{Q}}$ is defined as $\nu_{\mathrm{Q}}=e Q V_{z z} / h$. The EFG tensor has the principal axis components $\left\{V_{x x}, V_{y y}, V_{z z}\right\}$ and thus can be defined by its largest component $V_{z z}$ and its asymmetry parameter $\eta=\left(V_{x x}-V_{y y}\right) / V_{z z}$. The coefficients $s_{2 n}(\eta)$ and $g_{n}(\eta)$ are tabulated in $[23,24]$ for polyor monocrystalline samples. The term $\exp \left[-g_{n}(\eta) \delta t\right]$ accounts for a distribution of the EFG tensor of width $\delta$ at the well-defined $\eta$-value. Approximative expressions for $G_{2}(t)$ in the case of a small hyperfine field $B_{\mathrm{hf}}$ superimposed to a large EFG or vice versa have been derived e.g. by Wenzel et al. [25] and Raether et al. [26].

A general problem of PAC concerns the lattice site location(s) after implantation and the possible role of radiation damage. Originally, this problem was considered as the main obstacle for applying PAC in oxides, indeed. Our experience after implanting 400$\mathrm{keV}^{111} \mathrm{In}^{+}$ions at room temperature into a large number of oxides is that thermal annealing of the sample in oxygen or air at some $1000-1700 \mathrm{~K}$ for several hours in general leads to removal of almost all radiation damage. In case of existence of higher oxide phases, the annealing was carried out under a protective gas or in vacuum. So far we have performed ${ }^{111}$ In-PAC studies in more than 35 binary oxides [27 - 33] and 20 ternary oxides of perovskite, cuprate and delafossite structure [34-40] and found good evidence that in all cases large fractions of the probe atoms reached substitutional, defect-free implantation sites. As an example, we show in Fig. 1 the perturbation spectrum and Fourier transform obtained by Luthin et al. [32] after ${ }^{111}$ In implantation into $\mathrm{HfO}_{2}$ and a $4 \mathrm{~h}$-annealing at $1643 \mathrm{~K}$ in air. The spectra clearly exhibit the sub- stitutional EFG for ${ }^{111} \mathrm{In} /{ }^{111} \mathrm{Cd}$ on $\mathrm{Hf}$ sites as proven by comparison with $\mathrm{PAC}$ results on $\mathrm{HfO}_{2}$ using the self-atom ${ }^{181} \mathrm{Hf} /{ }^{181} \mathrm{Ta}$ (see Refs. in [32]). In several cases, REDOX phase transitions during the annealing process were observed to dramatically enhance the fraction ascribed to substitutional, defect-free sites in that oxide formed during the phase transition. In these cases, one may implant the probes into an oxygen-poorer phase and oxidize it further to the desired oxide matrix during annealing in air. A convincing example will be presented in Section 5 .

\section{Magnetic Phase Transitions in Oxides}

Oxides offer a large variety of magnetic phase transitions which have been studied in extenso via magnetometry, magneto-optical Kerr effect, neutron diffraction, Mössbauer effect [41], Nuclear Magnetic Resonance, muon Spin rotation, and other methods. PAC measurements are sensitive to the temperature variation of the magnetic hyperfine field(s) and therefore allow one to determine the critical parameters such as the phase transition (Néel) temperature $T_{\mathrm{N}}$ and critical exponent $\beta$ [42]. We have carried out PAC studies with implanted ${ }^{111}$ In probes e.g. for investigating the antiferromagnetic and ferrimagnetic ordering of $\mathrm{Mn}_{1-x} \mathrm{O}, \mathrm{Fe}_{1-x} \mathrm{O}, \mathrm{CoO}, \mathrm{NiO}, \mathrm{CuO}, \alpha-\mathrm{Fe}_{3} \mathrm{O}_{4}$ and $\mathrm{Co}_{3} \mathrm{O}_{4}$ [43 - 49]. On the basis of their non-cubic structures, several of these compounds exhibit one or several EFGs, leading to a combined magnetic/electric hyperfine interaction below $T_{\mathrm{N}}$ and a purely electric interaction above $T_{\mathrm{N}}$.

Figure 2 shows the temperature variation of $B_{\mathrm{hf}}$ obtained for ${ }^{111} \mathrm{Cd}$ in the anti-ferromagnet $\mathrm{CoO}$ [43]. 

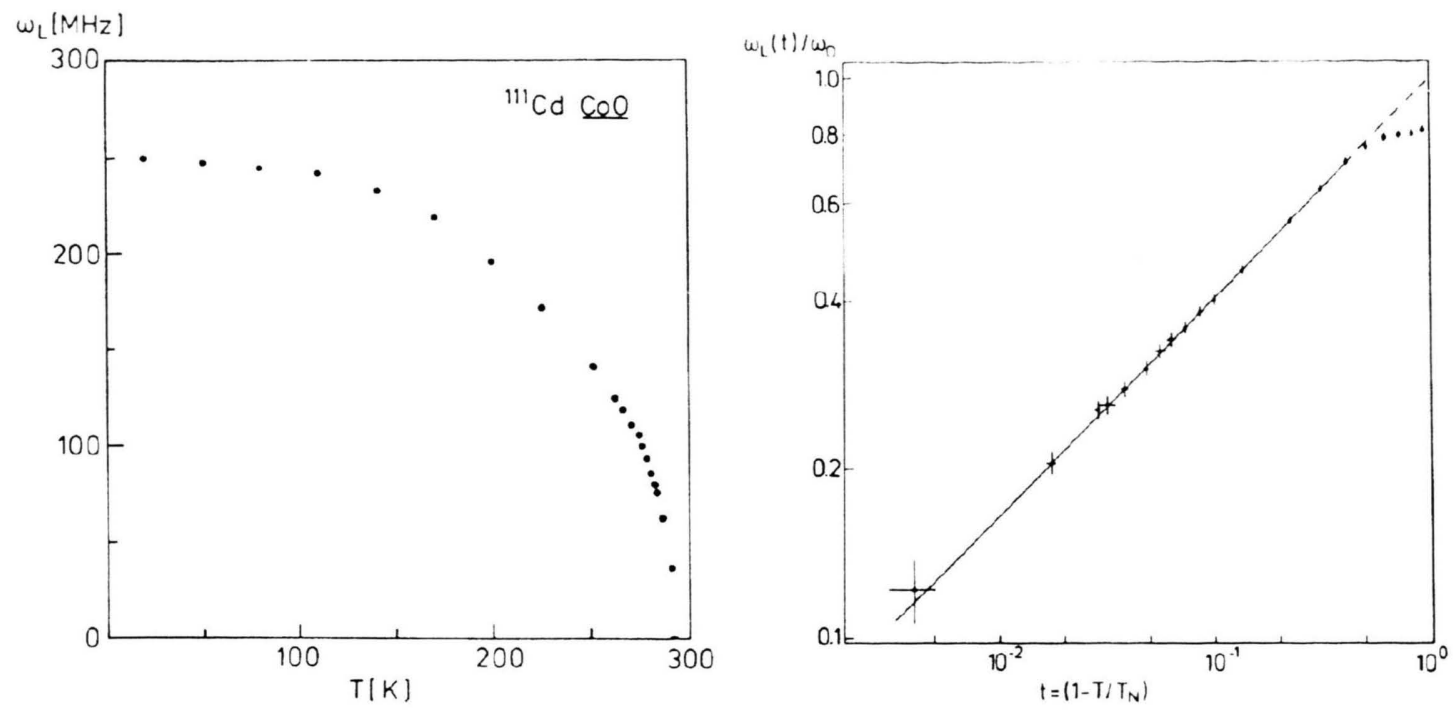

Fig. 2. Temperature variation (left) of the Larmor frequency for ${ }^{111} \mathrm{Cd}$ in $\mathrm{CoO}$ [43]. It follows a Curie-Weiss dependence with the critical parameters $T_{\mathrm{N}}=291.3(3) \mathrm{K}$ and $\beta=0.392(5)$ (right).

Table II. Critical parameters obtained from ${ }^{111}$ In-PAC spectroscopy for phase transitions in transitional metal oxides.

\begin{tabular}{|c|c|c|c|c|c|c|}
\hline Matrix & $\beta$ & $T_{\mathrm{N}}$ & $\omega(0)(\mathrm{MHz})$ & $t_{\min } \mathrm{b}$ & $t_{\max } \mathrm{b}$ & Ref. \\
\hline $\mathrm{Mn}_{1-x} \mathrm{O}$ & $0.24(1)$ & $88(2)$ & $283(2)$ & 0.001 & 0.65 & {$[47,48]$} \\
\hline $\mathrm{Fe}_{1-x} \mathrm{O}$ & a & & & & & [46] \\
\hline $\mathrm{CoO}$ & $0.393(5)$ & 291.3(3) & $307(2)$ & 0.004 & 0.4 & {$[42,44]$} \\
\hline $\mathrm{NiO}$ & $0.385(15)$ & $543(2)$ & $325(5)$ & 0.0013 & 0.5 & {$[5]$} \\
\hline $\mathrm{CuO}$ & $0.333(10)$ & $223(2)$ & $35(8)$ & 0.002 & 0.07 & {$[43,48]$} \\
\hline $\mathrm{Fe}_{3} \mathrm{O}_{4}$ & $0.392(2)_{\mathrm{A}}$ & $848(2)$ & $204(1)$ & 0.0035 & 0.65 & [45] \\
\hline & $0.392(2)_{B}$ & & & 0.0035 & 0.14 & \\
\hline & $0.39(1)_{A}$ & & & 0.004 & 0.02 & [59] \\
\hline $\mathrm{Co}_{3} \mathrm{O}_{4}$ & $\begin{array}{l}0.41(1)_{B} \\
0.34(2)\end{array}$ & $39(1)$ & $112(2)$ & 0.001 & 0.077 & {$[45,48]$} \\
\hline
\end{tabular}

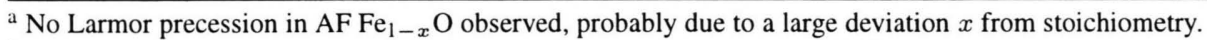

b The Curie-Weiss relation extends in the interval $\left(t_{\min }, t_{\max }\right)$, where $t=T / T_{\mathrm{N}}$.

Due to the $\mathrm{NaCl}$ structure of this oxide, the EFG vanishes. The normalized Larmor frequency $\omega_{\mathrm{L}}(\mathrm{T}) / \omega_{\mathrm{L}}(0)$ was found to follow a Curie-Weiss relationship $\omega_{\mathrm{L}}(\mathrm{t}) / \omega_{\mathrm{L}}(0)=t^{\beta}$ with $t=1-T / T_{\mathrm{N}}, T_{\mathrm{N}}=291.2(3) \mathrm{K}$ and $\beta=0.393(5)$, over the range $t=0.004$ to 0.4 . The critical parameters $T_{\mathrm{N}}$ and $\beta$ have also been obtained for the transitional metal monoxides $\mathrm{NiO}$ and $\mathrm{Mn}_{1-x} \mathrm{O}$ and for the inverse spinels $\mathrm{Fe}_{3} \mathrm{O}_{4}$ and $\mathrm{Co}_{3} \mathrm{O}_{4}$ (see Table II). In most cases, the $\beta$-values are very close to the one expected for 3D-Heisenberg spin ordering, $\beta_{\mathrm{H}}=0.385$. A rather detailed discussion of $\mathrm{Mn}_{1-x} \mathrm{O}, \mathrm{CuO}$, and $\mathrm{Co}_{3} \mathrm{O}_{4}$ was given by Wiarda et al. [48] and Bartos et al. [44, 49].

Comprehensive PAC studies of radiation-induced and intrinsic defects in $\mathrm{CoO}$ and $\mathrm{NiO}$ were carried out by Wenzel, Lieb, and Uhrmacher [25, 50]. In these measurements, taking PAC spectra below and above the respective Néel temperatures was essential to determine the fractions of probe nuclei on defectfree substitutional cation sites which, due to the cubic structure of these oxides, do not give rise to an electric quadrupole interaction. Two defect complexes featuring the same critical exponent, $\beta=0.39(1)$, as the defect-free fraction, but a different Néel temperature of $T_{\mathrm{N}}=505(2) \mathrm{K}$ were identified in NiO [25].

While the cubic structure of the transitional-metal monoxides leads to a purely magnetic interaction, combined magnetic / electric interactions occur in the inverse spinels $\mathrm{Co}_{3} \mathrm{O}_{4}$ and $\mathrm{Fe}_{3} \mathrm{O}_{4}$ [46], below the respective Néel temperatures. These circumstances 
a )

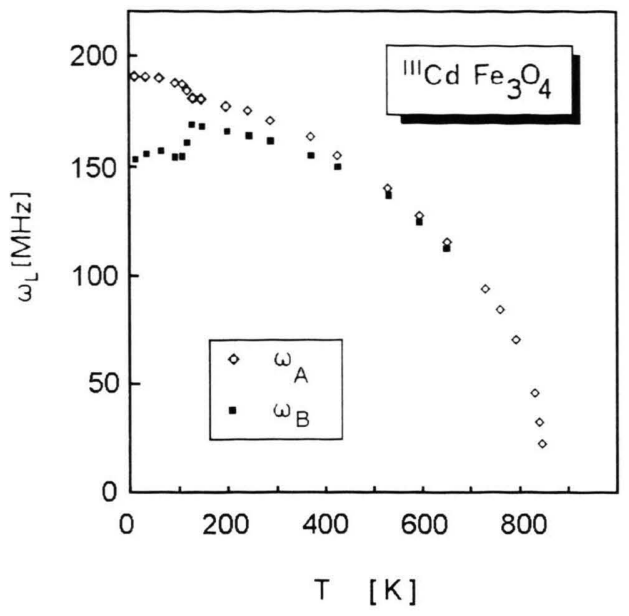

b)

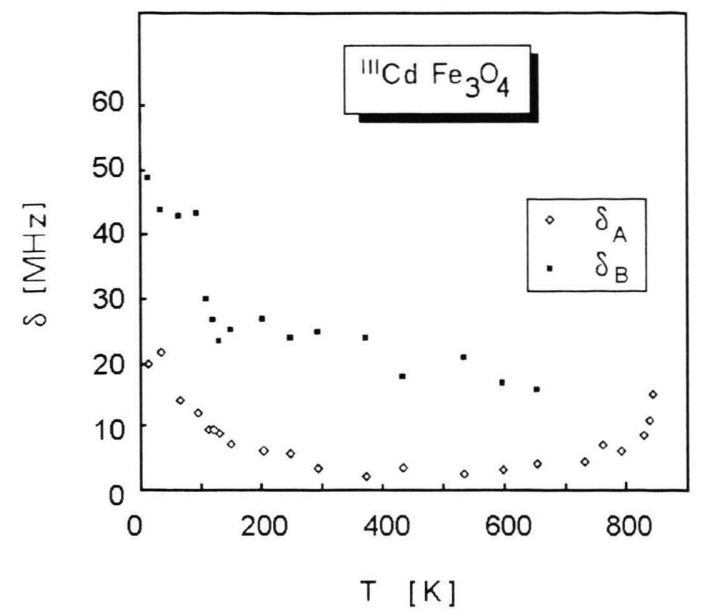

Fig. 3. Temperature variations of a) the Larmor frequencies $\omega_{\mathrm{LA}, \mathrm{B}}$ and b) width parameters $\delta_{\mathrm{A}, \mathrm{B}}$ for ${ }^{111} \mathrm{Cd}$ at the tetrahedral A site and octahedral $\mathrm{B}$ site in the inverse spinel $\mathrm{Fe}_{3} \mathrm{O}_{4}$, showing the ferrimagnetic phase transition at $\mathrm{T}_{\mathrm{N}}=848 \mathrm{~K}$ and the Verwey transition around $\mathrm{T}_{\mathrm{V}}=125 \mathrm{~K}[46,54]$.

limit the accessible temperature range and may lower the precision of the deduced critical parameters (see Table II). As an example, Fig. 3a illustrates the temperature dependence of the Larmor frequencies $\omega_{\mathrm{LA}}$ and $\omega_{\mathrm{LB}}$ measured for ${ }^{111} \mathrm{Cd}$, which most probably [51] substitutes the two cation sites A (tetrahedral; $\mathrm{Fe}^{3+}$ ) and $\mathrm{B}$ (octahedral; charge exchange between $\mathrm{Fe}^{2+}$ and $\mathrm{Fe}^{3+}$ ) in magnetite (= ferrimagnetic $\mathrm{Fe}_{3} \mathrm{O}_{4}$ ) [46]. It is interesting to note that the two values of $\beta_{\mathrm{A}}=\beta_{\mathrm{B}}=0.392(2)$ are in perfect agreement with each other and very close to the ones expected for a Heisenberg magnet. While the A-site oxygen surrounding is cubic $\left(\nu_{\mathrm{QA}}=0\right)$, the B-site features a finite, symmetric $\mathrm{EFG}, \nu_{\mathrm{OB}}=42(2) \mathrm{MHz}, \eta_{\mathrm{B}}=0$, measured at $T=873 \mathrm{~K}$, well above $T_{\mathrm{N}}=848 \mathrm{~K}$. The combined interaction at the site $\mathrm{B}$ below $T_{\mathrm{N}}$ leads to a line broadening in the EFG signal $\left(\delta_{\mathrm{B}}=20\right.$ $25 \mathrm{MHz}$, Fig. 3b) which is much larger than the one of the purely magnetic interaction at site $\mathrm{A}\left(\delta_{\mathrm{A}}=2\right.$ $5 \mathrm{MHz}$ ).

The temperature dependence of the magnetic hyperfine fields on the $\mathrm{A}$ and $\mathrm{B}$ sites in magnetite has been measured very carefully by means of ${ }^{57} \mathrm{Fe}-$ Mössbauer spectroscopy (MS) [52], while the sublattice magnetizations have been determined by neutron diffraction [53]. As discussed in detail by de Grave et al. [52], good agreement was found among the results of the two methods, but significant deviations from the $3 \mathrm{D}$ Heisenberg model! In the equation

$$
\omega_{\mathrm{Li}}(T) / \omega_{\mathrm{L} i}(0)=\left\langle S_{z i}(T)\right\rangle / S_{i}, i=\mathrm{A}, \mathrm{B},
$$

the quantity $\left\langle S_{z i}(T)\right\rangle$ is the expectation value of the $z$-component of the ionic spin $S_{i}$ at temperature $T$. It can be expressed as

$$
\left\langle S_{z i}(T)\right\rangle=\frac{B_{\mathrm{si}}}{k T}\left\{2 z_{i i} J_{i i}\left\langle S_{z i}(T)\right\rangle-2 z_{i j} J_{i j}\left\langle S_{z j}(T)\right\rangle\right\}
$$

where $B_{\mathrm{s} i}$ denotes the so-called Brillouin function at site $i, z_{i j}$ is the number of magnetic cations of type $j$ in the nearest-neighbor shell of cation $i$ and $J_{i j}$ the corresponding superexchange integral along the path $\mathrm{Fe}_{i-}-\mathrm{O}^{2-}--\mathrm{Fe}_{j}$. The calculated exchange integrals are $J_{\mathrm{AA}}=-11 \mathrm{~K}$ and $J_{\mathrm{AB}}=J_{\mathrm{BA}}=-22 \mathrm{~K}$. The value

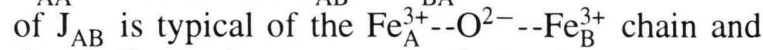
thus indicates ferrimagnetic ordering for the $\mathrm{AA}$ and $\mathrm{AB}$ pairs. The small positive value of $J_{\mathrm{BB}}=+3 \mathrm{~K}$ indicates ferromagnetic behavior for the $\mathrm{BB}$ pairs. These findings imply the validity of a conventional molecular-field approach of localized spins at the A site, but need to account for the non-localized sixth $3 \mathrm{~d}$ electron of the $\mathrm{Fe}^{2+}$ ion at the $\mathrm{B}$ site. Calculations with the non-localized electron model by Kubo and Ohata [54] have successfully reproduced the hyperfine field at the B site. The subtle difference between the MS and PAC data appears to be a consequence of the fact that no charge fluctuations occur for the ${ }^{111} \mathrm{Cd}$ probe, leading to an interpretation of both sites with localized electrons. This difference therefore is a first 

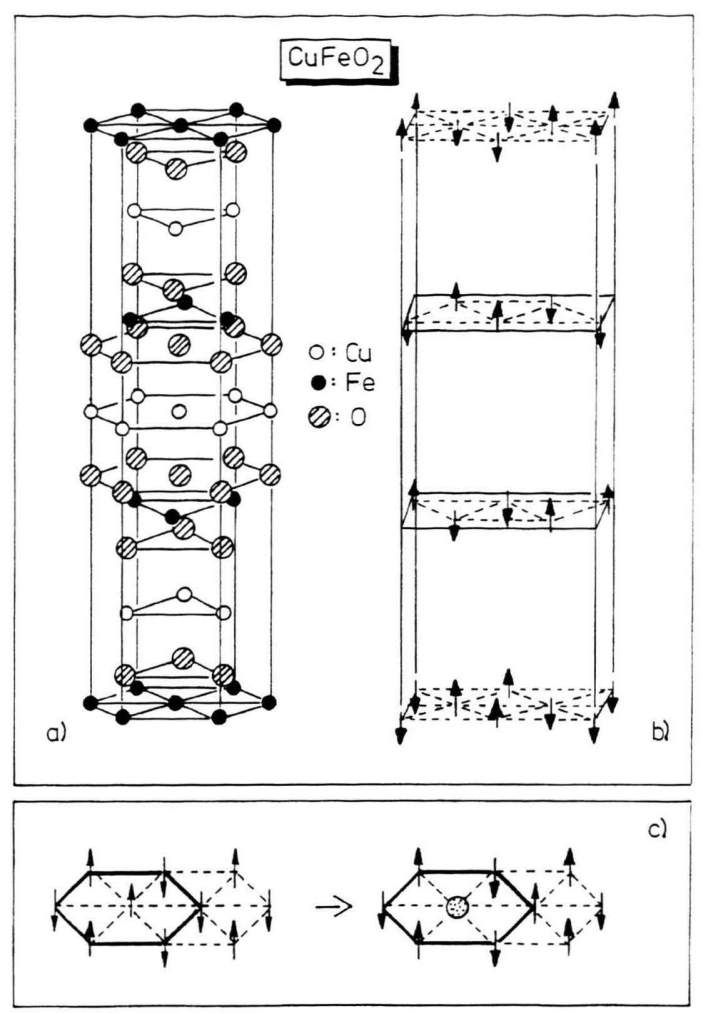

Fig. 4. Crystal structure of the $\mathrm{CuFeO}_{3}$ delafossite. The spin frustration within the 2D triangular Fe sublattice (left) is removed by substitutional ${ }^{111} \mathrm{In} /{ }^{111} \mathrm{Cd}$ impurity atoms (right). From [22].

indication that the impurity probe atom introduces a significant change into the system.

Another interesting phase transition of Verwey type in magnetite was studied with PAC [51]: This transition around $125 \mathrm{~K}$ is also visible in Fig. $3 \mathrm{a}$ as a sudden increase of $\omega_{\mathrm{LA}}$ from $178 \mathrm{MHz}$ at $140 \mathrm{~K}$ to $191 \mathrm{MHz}$ at $100 \mathrm{~K}$. In the same temperature interval, the Larmor frequency $\omega_{\mathrm{LB}}$ drops from $173 \mathrm{MHz}$ to $151 \mathrm{MHz}$ (see Fig. 3a), while both $\delta_{\mathrm{A}}$ and $\delta_{\mathrm{B}}$ strongly increase below $T_{\mathrm{V}}$ (Figure $3 \mathrm{~b}$ ). The dramatic changes of the Larmor frequencies $\omega_{\mathrm{LA}, \mathrm{B}}$ and distribution widths $\delta_{\mathrm{A}, \mathrm{B}}$ at the Verwey transition have been correlated with either the presence of several hyperfine environments below $T_{\mathrm{V}}$ which were also seen in Mössbauer spectroscopy [52, $55,56]$, the structural phase transition from cubic to monoclinic structure, and/or electronic after-effects (due to the change of the conductivity at $T_{\mathrm{V}}$ from conductor to insulator).

So far, the role of the dilute ${ }^{111} \mathrm{In} /{ }^{111} \mathrm{Cd}$ probe atoms was that of more or less ideal "spectators" monitoring
PAC - data
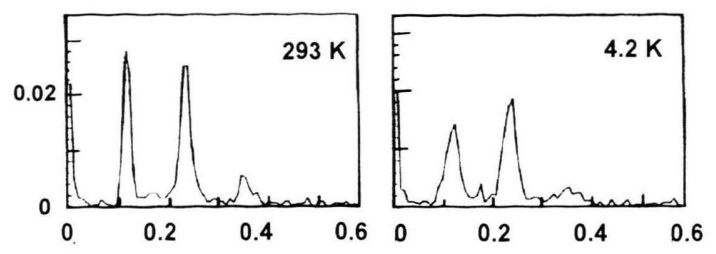

simulation

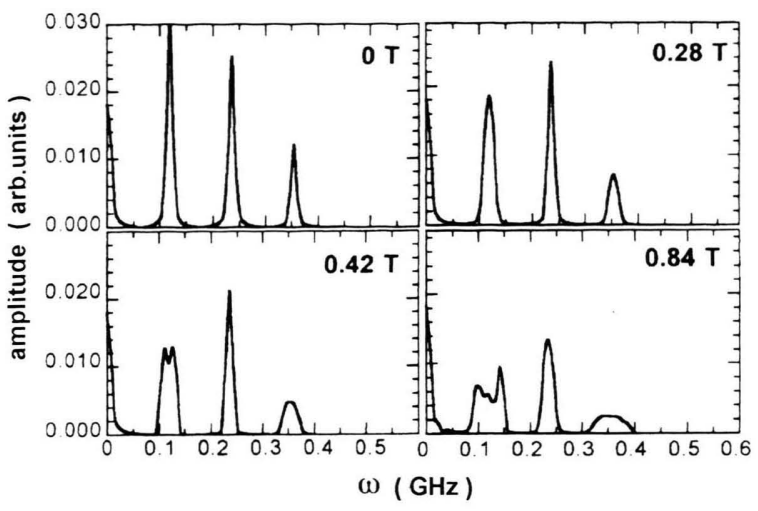

Fig. 5. Measured and calculated Fourier transforms of combined electric and magnetic hyperfine interactions in $\mathrm{CuFeO}_{3}$ in the limit of a small magnetic hyperfine field [22]. $\mathrm{T}$ means Tesla.

the magnetic ordering of the matrix without influencing it. A contrasting behavior was found in the case of polycrystalline $\mathrm{CuFeO}_{2}$, where the probes on particular lattice sites determine the spin ordering [22]. The crystal structure of the $\mathrm{A}^{1+} \mathrm{B}^{3+} \mathrm{O}^{2-}{ }_{2}$ delafossite $\mathrm{CuFeO}_{2}$, Fig. 4, can be seen as a sequence of monoatomic layers, all with triangular structure. The magnetically ordering Fe layers are separated from each other by two oxygen layers and a Cu layer. This leads to a $2 \mathrm{D}$ spin-frustrated $\mathrm{AF}$ within the triangular $\mathrm{Fe}$ sublattice. When the magnetic hyperfine field below the Néel temperatures $T_{\mathrm{N}}=11 \mathrm{~K}$ and $16 \mathrm{~K}$ was mea-

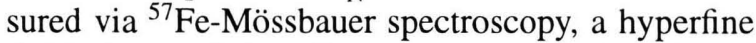
field of normal size, $B_{\mathrm{hf}}=51.7 \mathrm{~T}$, was identified at $4.2 \mathrm{~K}$ for the $\mathrm{Fe}$ site, besides the occurrence of a large EFG [57]. On the other hand, when the hyperfine field was measured via ${ }^{111} \mathrm{In}-\mathrm{PAC}$, the resulting value of $B_{\mathrm{hf}}=0.3(1) \mathrm{T}$ was found to be much smaller. This low value of $B_{\mathrm{hf}}$ was explained by the regular antiparallel spin ordering of the six immediate Fe neighbors around the ${ }^{111} \mathrm{Cd}$ probe whose hyperfine fields should cancel each other, because now the spin frustration is relieved (see Figure 4). The Fourier spectra of the perturbation functions measured below $T_{\mathrm{N}}\left(T_{\mathrm{m}}=4.2 \mathrm{~K}\right)$ 


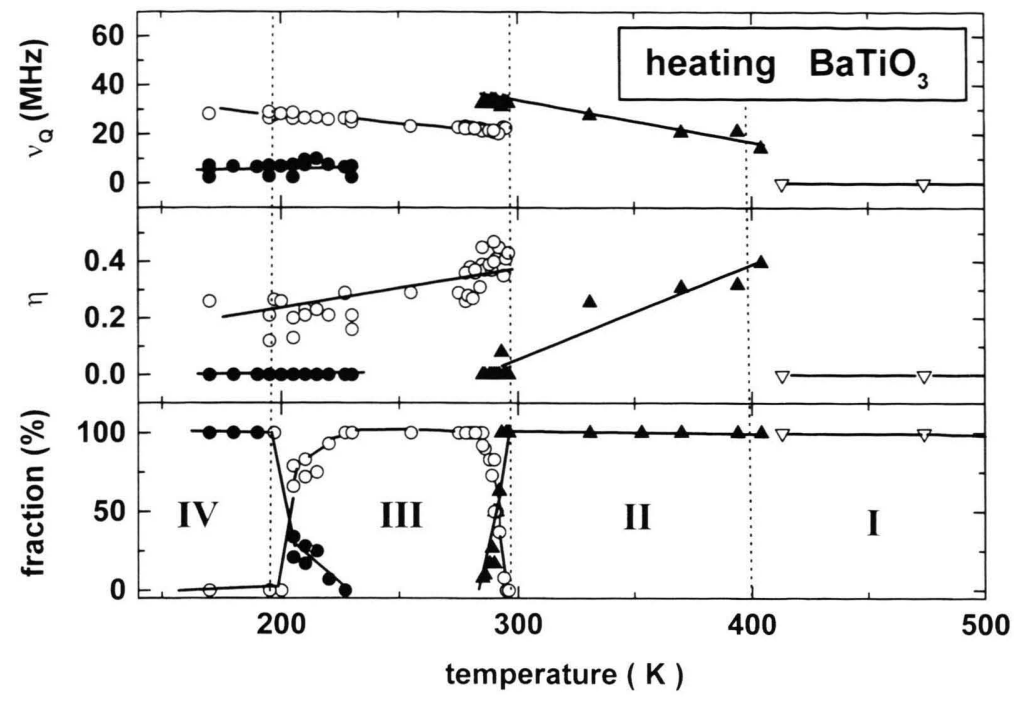

Fig. 6. Temperature variation of the ${ }^{111} \mathrm{Cd}$ electric quadrupole interaction parameters $\nu_{\mathrm{Q}}, \eta$ and the fraction of different EFGs for $\mathrm{BaTiO}_{3}$. Dashed lines mark the phase transitions according to the literature.

show a broadening and reduction in height of the first EFG harmonics $\omega_{1}$, relative to that measured above $T_{\mathrm{N}}\left(T_{\mathrm{m}}=293 \mathrm{~K}\right)$. The simulated Fourier spectra shown in Fig. 5 confirm the small value of $B_{\mathrm{hf}}$. The interpretation rests on the assumption that ${ }^{111}$ In occupies the $B^{3+}(\mathrm{Fe})$ sites. Support for this interpretation came firstly from the magnitude and asymmetry of the EFG and secondly from PAC experiments with ${ }^{111} \mathrm{Ag}$ probe atoms which, of course, occupy the $\mathrm{A}^{1+}$ sites and therefore exhibit a very different EFG [36]. Both types of EFGs were also found in the PAC data obtained with ${ }^{111} \mathrm{Ag}$ or ${ }^{111}$ In probes in the delafossite $\mathrm{AgInO}_{2}$ where the probes are self-atoms.

\section{Structural Phase Transitions}

While magnetic phase transitions only involve changes of spin directions, we now proceed to the discussion of phase transitions, due to changes in the atomic positions, but still not in the composition of the compounds. Perovskite oxides of the structure $\mathrm{A}^{2+} \mathrm{B}^{4+} \mathrm{O}_{3}^{2-}$ exhibit complex structural instabilities such as ferroelectric or antiferroelectric distortions, which have been investigated extensively [58]. A perfect perovskite crystal has full cubic symmetry and can be imagined as a lattice of corner-sharing oxygen octahedra. Cation B - the smaller one - is located in the center of an oxygen octahedron, whereas cation $\mathrm{A}$ is at the 12-fold coordinated site between the octahedra. Typical structural phase transitions concern either the octahedral network (tilting or twisting the octahedra towards each other), the individual shapes
Table III. Electric field gradients of ${ }^{111} \mathrm{Cd}$ and ${ }^{181} \mathrm{Ta}$ probes in $\mathrm{BaTiO}_{3}$, at the given temperatures [39].

\begin{tabular}{lrclrll}
\hline Probe nucleus & \multicolumn{3}{c}{${ }^{111} \mathrm{Cd}$} & \multicolumn{3}{c}{${ }^{181} \mathrm{Ta}[4-6]$} \\
Phase & $T(\mathrm{~K}) \nu_{\mathrm{Q}}(\mathrm{MHz})$ & $\eta$ & $T(\mathrm{~K})$ & $\nu_{\mathrm{Q}}(\mathrm{MHz})$ & $\eta$ \\
\hline IV, rhomboh. & 80 & $6.3(24)$ & 0 & 80 & $63(17)$ & 0 \\
III, orthorh. & 227 & $22.0(8)$ & $0.37(6)$ & 220 & $137(12)$ & $0.4(1)$ \\
II, tetragonal & 293 & $33.3(7)$ & 0 & 293 & $205(12)$ & 0 \\
I, cubic & 475 & 0 & 0 & 400 & 0 & 0 \\
\hline
\end{tabular}

of the octahedra (deformations along the axes) or the location of the cations, which may be shifted out of their central positions.

We have performed PAC measurements with implanted ${ }^{111}$ In probes to study structural phase transitions in $\mathrm{BaTiO}_{3}, \mathrm{SrTiO}_{3}, \mathrm{BaHfO}_{3}, \mathrm{SrHfO}_{3}$ and $\mathrm{PbZrO}_{3}$ perovskites [37 - 39]. When the temperature is raised from 150 to $400 \mathrm{~K}, \mathrm{BaTiO}_{3}$ - of highest interest due to its piezoelectric properties [59] - undergoes three well known phase transitions: rhombohedral (IV) $\rightarrow$ orthorhombic (III) $\rightarrow$ tetragonal (II) $\rightarrow$ cubic (I). The changes between the phases involve tiny shifts of the Ti-positions in the order of only $6 \mathrm{pm}$, together with slight distortions of the oxygen octahedron [60]. Figure 6 compiles the EFG parameters $\nu_{\mathrm{Q}}$ and $\eta$ of the different phases during heating sequences. Each phase is characterized by a single EFG (with a fraction of 100\%), different in strength and symmetry. The PAC parameters are listed in Table III. The ferrielectric transitions IV $\rightarrow$ III and III $\rightarrow$ II are structural phase transitions of first order with a discontiuous change of the order parameter. As a consequence a certain temperature range exists where both 


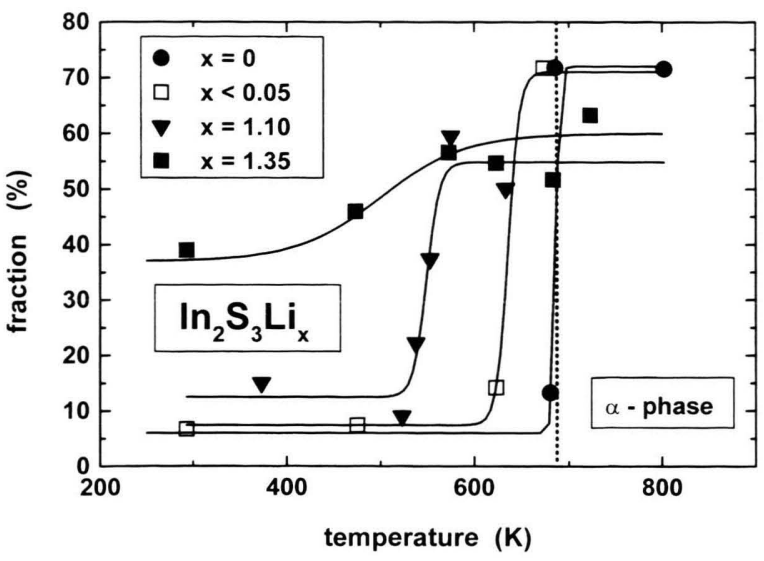

Fig. 7. Temperature dependence of the occurrence of an $\alpha$-phase like fraction in $\beta$ - $\operatorname{In}_{2} \mathrm{~S}_{3}$ samples which have been doped with different amounts $x$ of Li-atoms.

phases coexist, giving rise to an hysteresis. If we define the transition temperature $T_{0}$ by requiring that both fractions reach $50 \%$, the hysteresis leads to two transition temperatures $T_{0} / \downarrow$ for heating and cooling cycles, separated by the interval $\Delta T=\left|T_{0}{ }^{\dagger}-T_{0} \downarrow\right|$. As shown in detail in [40], in the case of $\mathrm{BaTiO}_{3}$ we found $\Delta T=7.5 \mathrm{~K}$ for the IV $\rightarrow$ III transition and $\Delta T=$ $6.1 \mathrm{~K}$ for the III $\rightarrow$ II transition. Compared to other methods there are slight differences in the values of $\Delta T$ and also in $T_{0}$, but PAC surely is the most local indicator of the hysteresis [40]. The temperature dependence of the parameters $\nu_{\mathrm{Q}}$ and $\eta$ in each phase shown in Fig. 6 can easily be explained by the thermal changes of the lattice constants in these phases, as will be shown below.

Another type of structural phase transitions related to changes in the next-neighbor polyhedra occurs in the spinel $\mathrm{In}_{2} \mathrm{~S}_{3}$. In the $\beta$-phase the self-atom ${ }^{111} \mathrm{In}$ occupies all possible cation sites of the sulphur-polyhedra, according to the probabilities imposed by the crystallographic order. These are two octahedral sites $\mathcal{O}_{1}$ and $\mathcal{O}_{2}$ of somewhat different geometry and one tetrahedral site $\mathcal{T}$. Nevertheless, one third of all existing coordination tetrahedra is not occupied by In-ions, in a fixed crystallographic order. The phase transition to the cubic $\alpha$-phase occurs at $T=693 \mathrm{~K}$ and results in a random order of the non-occupied tetrahedra. In fact, the PAC spectra show a dynamical behaviour (see Sect. 5) which is attributed to In-ions jumping between empty S-tetrahedra, within the PAC observation time [62]. A high amount $x$ of Li-atoms can be intercalated into the spinel structure (on non-regular lattice sites) to form $\beta-\mathrm{In}_{2} \mathrm{~S}_{3} \mathrm{Li}_{x}$. As shown in Fig. 7, a dramatic reduction of the phase transition temperature occurs for increasing Li content $x$. The observed PAC parameters are equal to those, found in the $\mathrm{Li}$ free $\alpha$-phase. Therefore, one has to assume that the electrically active Li-atoms lower the binding of the In-ions inside a sulphur tetrahedra: now the In-ions jump between empty tetrahedra which results in the random distribution of the $\alpha$-phase.

\section{Excursion to the Calculation of EFGs in Oxides}

In many oxides, PAC measurements have been carried out with the standard probes ${ }^{111} \mathrm{In} /{ }^{111} \mathrm{Cd}$ and ${ }^{181} \mathrm{Hf} /{ }^{181} \mathrm{Ta}$. For the quadrupole frequencies $\nu_{\mathrm{Q}}$ associated with substitutional, defect-free sites, their ratio was in general found in agreement with the value $\nu_{\mathrm{Q}}\left({ }^{181} \mathrm{Ta}\right) / \nu_{\mathrm{Q}}\left({ }^{111} \mathrm{Cd}\right)=6.5 \pm 1.0$ predicted by the Point Charge Model (PCM). In addition, agreement was found for the experimental asymmetry parameters $\eta$. In the following, we shortly discuss some of the successes and failures of PCM and the possibility to identify lattice locations and refine atomic positions. This, of course, directly bears on the possibility of following structural phase transitions.

EFGs can be calculated $a b$ initio, even in complex compounds [63], if an appropriate band structure description of that compound is available. Whenever the bonding of oxides can be supposed to be mainly ionic, a simple PCM may be applied to calculate the EFG for probes at cation sites, as was shown by Frantz et al. from a comparison of PCM with a HartreeFock and a LAPW calculation [64]. Assuming formal point charges for the anions and cations at their crystallographic locations, the lattice sum $V_{i j}$ lat can be calculated [7, 28]. As to the problem of convergence of the lattice sum in the case of the $r^{-3}$ dependence of the EFG and the $r^{3}$ dependence of the integration volume, convergence was found in all cases when a cut-off radius of $5 \mathrm{~nm}$ around the probe ion was used [7]. Writing the EFG tensor at the probe nucleus as $V_{i j}=\left(1-\gamma_{\infty}\right) V_{i j}$ lat and using the known Sternheimer antishielding factors $\gamma_{\infty}\left({ }^{111} \mathrm{Cd}\right)=-29.27$ and $\gamma_{\infty}\left({ }^{181} \mathrm{Ta}\right)=-68.12[65]$ and quadrupole moments $Q\left({ }^{111} \mathrm{Cd}\right)=0.83(13) \mathrm{b}$ and $Q\left({ }^{181} \mathrm{Ta}\right)=2.36(5) \mathrm{b}$ [4], respectively, one finds the ratio $\nu_{\mathrm{Q}}(\mathrm{Ta}) / \nu_{\mathrm{Q}}(\mathrm{Cd})=$ 6.5(10) [37]. Table IV summarizes EFG parameters of several perovskites and of monoclinic $\mathrm{HfO}_{2}$ and $\mathrm{ZrO}_{2}$ and indeed demonstrates the usefulness of the PCM to identify substitutional sites in these oxides. 


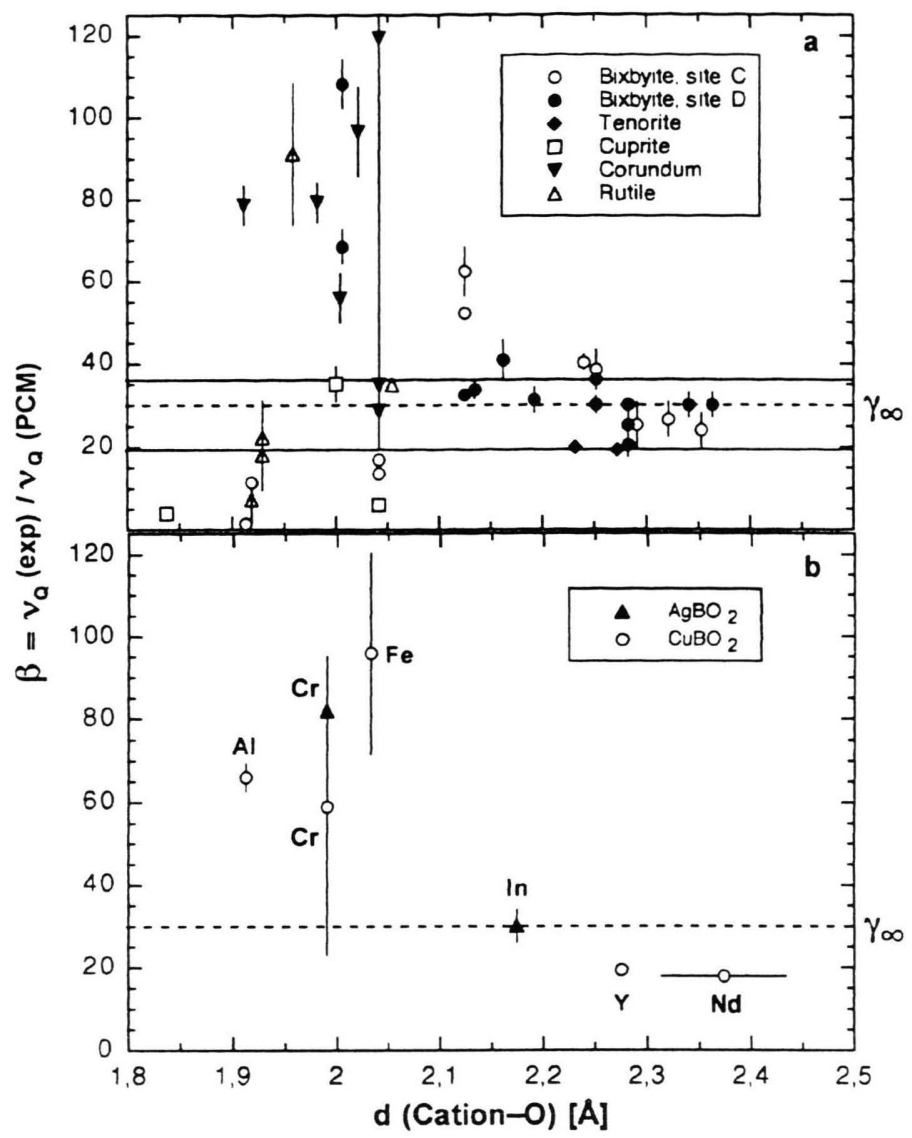

Fig. 8. The ratio $\beta=\nu_{\mathrm{Q}}(\exp ) / \nu_{\mathrm{Q}}(\mathrm{PCM})$ is plotted versus the bond length $d$ (cation-O) in oxides (a) taken from the compilation in [7] and (b) from the delafossite data of $[35,36]$

Table IV. Comparison of the quadrupole interaction with ${ }^{181} \mathrm{Ta}$ and ${ }^{111} \mathrm{Cd}$ probes in non-cubic compounds [38].

\begin{tabular}{lllllll}
\hline & & \multicolumn{2}{c}{${ }^{181} \mathrm{Hf} /{ }^{181} \mathrm{Ta}$} & \multicolumn{2}{c}{${ }^{111} \mathrm{In} /{ }^{111} \mathrm{Cd}$} \\
Comp. & Struct. & $\nu_{\mathrm{Q}}(\mathrm{MHz})$ & $\eta$ & $\nu_{\mathrm{Q}}(\mathrm{MHz})$ & $\eta$ & $\frac{\nu_{\mathrm{Q}}(\mathrm{Ta})}{\nu_{\mathrm{Q}}(\mathrm{Cd})}$ \\
\hline $\mathrm{SrHfO}_{3}$ & orthorh. & $130(4)$ & $0.45(6)$ & $21.6(13)$ & $0.51(6)$ & $6.0(3)$ \\
$\mathrm{PbZrO}_{3}$ & orthorh. 522(6) & 0.84 & $93(5)$ & $\approx 1$ & $5.6(3)$ \\
$\mathrm{BaTiO}_{3}$ & tetrag. & $205(5)$ & $0.15(5)$ & $31.2(30)$ & $0.25(6)^{\mathrm{a}}$ & $6.6(8)$ \\
$\mathrm{HfO}_{2}$ & monocl. $783(6)$ & $0.34(3)$ & $111(2)$ & $0.60(3)$ & $7.1(2)$ \\
$\mathrm{ZrO}_{2}$ & monocl. $719(6)$ & 0.33 & $111(2)$ & $0.64(4)$ & $6.5(2)$ \\
$\mathrm{PCM}$ & & & & & $6.5(12)$ \\
\hline
\end{tabular}

a mean value over the whole range of phase existence.

More important in the context of structural phase transitions was the systematic investigation of the $r^{-3}$ dependence of the EFG. We used classes of oxides having the same crystalline structure, but different lattice constants. In this way, the cation bond lengths were varied in a controlled way. Extensive studies were done in the bixbyites $\left(\mathrm{A}^{3+}{ }_{2} \mathrm{O}^{2-}{ }_{3}\right)$, among them the only stable indium oxide $\mathrm{In}_{2} \mathrm{O}_{3}[30$, $66,67]$. A second class for such studies were the cuprates $\mathrm{M}_{2} \mathrm{Cu}_{2} \mathrm{O}_{5}$ [34] and finally the delafossites $\mathrm{A}^{1+} \mathrm{B}^{3+} \mathrm{O}^{2-}{ }_{2}$ which span the widest range of lattice parameters [35]. In all three classes a smooth dependence of the EFG parameters $\nu_{\mathrm{Q}}$ and $\eta$ on the average bond length $\langle d\rangle^{-3}$ was found. An appropriate way to illustrate the result of this comparison is plotting the ratio $\beta(\exp )=\nu_{\mathrm{Q}}(\exp ) / \nu_{\mathrm{Q}}(\mathrm{PCM})$ versus the bond length $\langle d\rangle$ averaged over all next-neighbor oxygen ions (see Fig. 8 [35]). Most data with $\langle d\rangle \geq 2.1 \AA$ are found within the range $19 \leq \beta(\exp ) \leq 36$. The weighted experimental average is $\beta \geq 32(2)$ which is in good agreement with the calculated value $\beta_{\infty}=$ $\left(1-\gamma_{\infty}\left({ }^{111} \mathrm{Cd}\right)\right)=30.3$, given as the dotted line. For smaller bond lengths, the data seem to split into two branches, one with the high value of $\beta \approx 85$ and the other one with values below $\beta \approx 10$. The critical distance of $2.1 \AA$ has a simple interpretation: it is the sum of the Shannon radii [68] of $\mathrm{O}^{2-}$ and $\mathrm{Cd}^{2+}$ ions. A shorter distance is equivalent to an overlap of the electronic shells, giving rise to covalent bonding and additional contributions to the EFG, possibly with dif- 


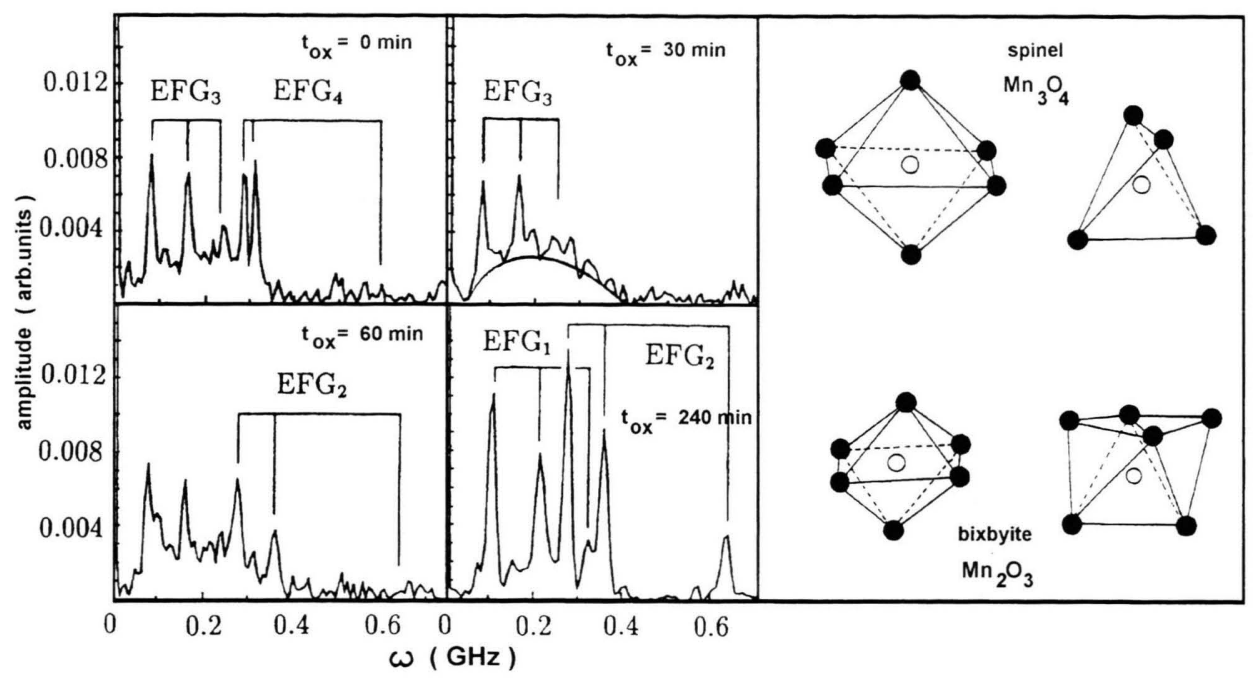

Fig. 9. Fourier transforms of PAC spectra taken at $480 \mathrm{~K}$ and $p \leq 10^{-5}$ mbar after oxidizing $\mathrm{Mn}_{3} \mathrm{O}_{4}$ at $770 \mathrm{~K}$ for different times $t_{\mathrm{ox}}$. On the right hand side the different oxygen-polyhedra and their transformations are indicated [48,9].

ferent signs. The delafossite data displayed in Fig. 8b gave more insight into the questions, whether $\beta$ depends on the crystalline structure or on the bond length or whether it clusters within certain regions of bond lengths. The delafossite data extend over the whole range of $\langle d\rangle$ covered by the binary oxides shown in Fig. 8a and feature a smooth dependence [35, 36].

Finally, we shall discuss the accuracy in determining crystalline coordinates in the class of bixbyite oxides by means of PAC. The determination of atomic positions of the light elements in compounds made from atoms of very different element number $Z$ by $\mathrm{X}$-ray diffraction is complicated. In oxides containing very heavy metal components, one usually relies on neutron diffraction. Realizing the pronounced scatter of calculated EFG parameters in the bixbyite oxides when using the published structure data in the PCM calculations, Bartos et al. [28] in turn used the precisely measured quadrupole interaction parameters to refine the atomic positions to a precision of better than $1 \mathrm{pm}$ and still found agreement with the less precise coordinates obtained from X-ray and neutron diffraction [28]. The new bond lengths vary smoothly with the lattice constants. As an additional test, Lupascu et al. [30] performed precision PAC measurements in $\mathrm{Er}_{2} \mathrm{O}_{3}$ and $\mathrm{Ho}_{2} \mathrm{O}_{3}$ single crystals and achieved a refinement at the level $1 * 10^{-4}$. The coordinates obtained in this way agreed with the high-precision Xray diffraction data taken for the same crystals.
Having in mind this high sensitivity of PAC to small variations of atomic coordinates, Krishnamurthy et al. [69] studied the spin-Peierls phase transition in $\mathrm{CuGeO}_{3}$ using ${ }^{111} \mathrm{In}-\mathrm{PAC}$. Below the critical temperature of $T_{\mathrm{SP}}=14 \mathrm{~K}$, adjacent $\mathrm{Cu}^{2+}$ ions undergo spin dimerization and form $\mathrm{Cu}^{2+}-\mathrm{Cu}^{2+}$ pairs along the $c$-axis, verified by differnt techniques as $\mathrm{X}$-ray diffraction, electron- and neutron diffraction (see Ref. in [69]. When these $\mathrm{Cu}$-dimers are built, the distance between the dimers is slightly larger than the distance within the pair. This shift is accompanied by alternating inward and outward displacements of the two $\mathrm{O}^{2-}$ ions in the $\mathrm{Cu}-\mathrm{O}-\mathrm{Cu}$ chains along the $c$-axis. These positional changes at the structural phase transition might change the asymmetry parameter $\eta$ and/or the EFG. However, no effect was observed: either these positional changes are too small to be detected, or we find again the influence of the impurity probe atom. The In atom cannot build a dimer with $\mathrm{Cu}$ and locally destroys the spin-Peierls transition.

\section{REDOX Phase Transitions in Oxides}

Phase diagrams of metals and oxygen often show the existence of several stable oxide phases with different stoichiometries. Consequently, many metals in contact with air build oxide surface layers, sometimes sequences of layers with different oxide stoichiometries. Problems of corrosion, atomic transport during 

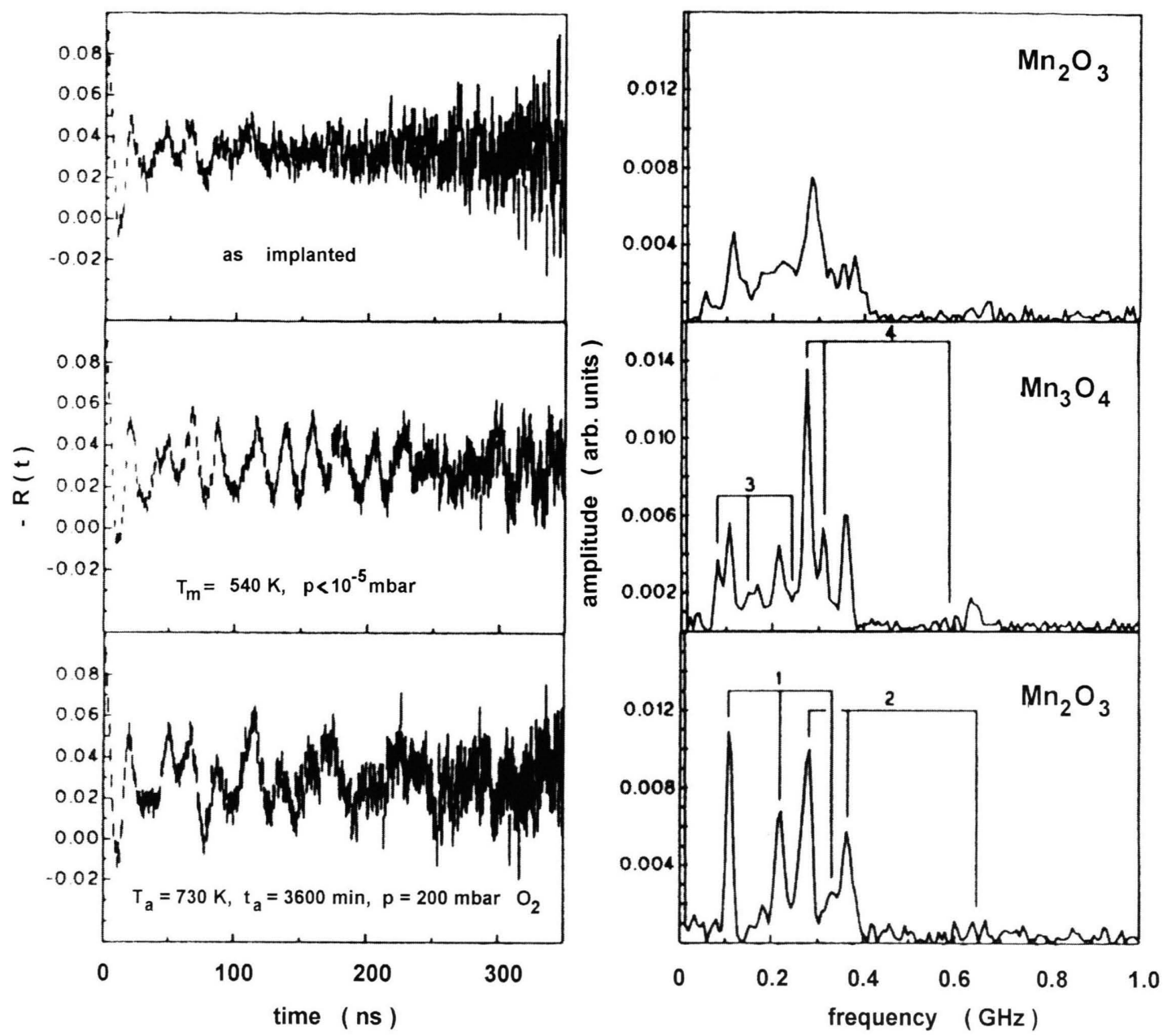

Fig. 10. PAC spectra of a complete REDOX phase transition cycle. After the implantation of ${ }^{111}$ In into $\mathrm{Mn}_{2} \mathrm{O}_{3}$ (top) this oxide was reduced to $\mathrm{Mn}_{3} \mathrm{O}_{4}$ at $540 \mathrm{~K}$ in high vacuum and measured under these conditions (middle). An oxidation at $730 \mathrm{~K}$ for $60 \mathrm{~h}$ restored $\mathrm{Mn}_{2} \mathrm{O}_{3}$. This spectrum was taken at room temperature $[48,73]$.

oxidation and/or the occurrence of defects call for a microscopic observation of oxidation and reduction reactions. Such REDOX phase transitions dramatically change the crystalline structure, i. e. the oxygen polyhedra and/or the charge state(s) of the cation(s). In general, all these phenomena can be observed by the PAC technique. However, when realizing such REDOX phase transitions experimentally, a kind of asymmetry occurs: heating metals or lower oxides in oxygen easily increases the oxygen content of the sample. On the other hand, annealing treatments of an oxide under a standard vacuum is - in most cases not enough to achieve a reduction. As an example, the rutile $\mathrm{TiO}_{2}$ can only be reduced to $\mathrm{Ti}_{3} \mathrm{O}_{5}$ via an increasing oxygen deficit under the very low oxygen partial pressure of $10^{-9} \mathrm{hPa}$ at $1600 \mathrm{~K}[70,71]$. Therefore, a thermal treatment below $1600 \mathrm{~K}$ under a pumped vacuum of $10^{-5} \mathrm{hPa}$ does not reduce any Ti-oxid. Experimentally such a low oxygen activity can be realized by using a controlled gas mixture of $\mathrm{CO}$ and $\mathrm{CO}_{2}$, as was applied in the PAC studies on $\mathrm{CoO}, \mathrm{NiO}$ and $\mathrm{Cr}_{2} \mathrm{O}_{3}[50,72,25,31]$.

As an example, we present results on the REDOX phase transition in manganese oxides obtained by Wiarda and collaborators [48]. The phase transition between the spinel $\mathrm{Mn}_{3} \mathrm{O}_{4}$ and the bixbyite $\mathrm{Mn}_{2} \mathrm{O}_{3}$ can be driven in both directions without big experimental difficulties. Figure 9 illustrates the oxidation 
of $\mathrm{Mn}_{3} \mathrm{O}_{4}$ to $\mathrm{Mn}_{2} \mathrm{O}_{3}$ at $770 \mathrm{~K}$ in $200 \mathrm{mbar}_{2}$ for increasing oxidation times $t_{\mathrm{ox}}$. The evolution of the oxidation process was followed by accumulating the PAC spectra at $T_{\mathrm{m}}=480 \mathrm{~K}$ in high vacuum [48]. Each of the two crystal structures contains two non-equivalent cation sites represented at the right hand side of Fig. 9 by their characteristic oxygen polyhedra. Surprisingly, the phase conversion seems to proceed stepwise and with different velocities for the different polyhedra. First the signal $\mathrm{EFG}_{4}$ from ${ }^{111} \mathrm{In}$-ions occupying tetrahedral sites in $\mathrm{Mn}_{3} \mathrm{O}_{4}$ (four next neighbors at $2.63 \AA$ ) converts into a broad distribution, while the octahedral site (two NN at $2.29 \AA$ and four at $2.63 \AA$, symmetric $\mathrm{EFG}_{3}$ ) remains stable. The octahedron in $\mathrm{Mn}_{3} \mathrm{O}_{4}$ is still dominantly present $\left(\mathrm{EFG}_{3}\right)$ when a large amount of probes already feels the asymmetric octahedron of $\mathrm{Mn}_{2} \mathrm{O}_{3}\left(6 \mathrm{NN}\right.$ at $\left.2.04 \AA, \mathrm{EFG}_{2}\right)$. In this state, the structure of the sample is neither a spinel nor a bixbyite! Finally, the environments of the remaining probes reorder to form the symmetric octahedra (six $\mathrm{NN}$ at $2.003 \AA$ ) giving rise to $\mathrm{EFG}_{1}$. X-ray diffraction before and after the phase transition showed a complete transformation of the full polycrystalline sample. It should be mentioned here that $\mathrm{Mn}_{3} \mathrm{O}_{4}$ is one of the very rare cases where the ${ }^{111}$ In probes are found at the center of an oxygen tetrahedron. In fact, during the oxidation process, this site disappears first. On the other hand, the right hand side of Fig. 9 suggests, that the tetrahedron can easily be transformed into the irregular octahedron by attracting two more oxygen ions in an upper plane.

Figure 10 shows PAC data accumulated during the reduction reaction of the same Mn-oxides [73]. ${ }^{111} \mathrm{In}$ was implanted into $\mathrm{Mn}_{2} \mathrm{O}_{3}$. Due to radiation damage the oscillations in the PAC spectra are damped in the as-implanted spectrum. The second spectrum measured at $T_{\mathrm{m}}=540 \mathrm{~K}$ under high vacuum conditions exhibits the EFGs typical of $\mathrm{Mn}_{3} \mathrm{O}_{4}$. The subsequent oxidation at $730 \mathrm{~K}$ with 200 mbar $\mathrm{O}_{2}$ for 60 hours leads back to a well defined $\mathrm{Mn}_{2} \mathrm{O}_{3}$ spectrum, measured at room temperature. Figure 10 thus illustrates a complete cyclic REDOX phase transition and proves that this kind of phase transition efficiently anneals out radiation damage: after this rearrangement of the whole sample, large fractions of the implanted ${ }^{111}$ In probes sit on well-defined substitutional sites.

From a chemical point of view REDOX phase transitions change the charge state of ions in the compound. In oxides the $\mathrm{O}$ ions usually stay in the charge state -2 , while the charge state(s) of the cations

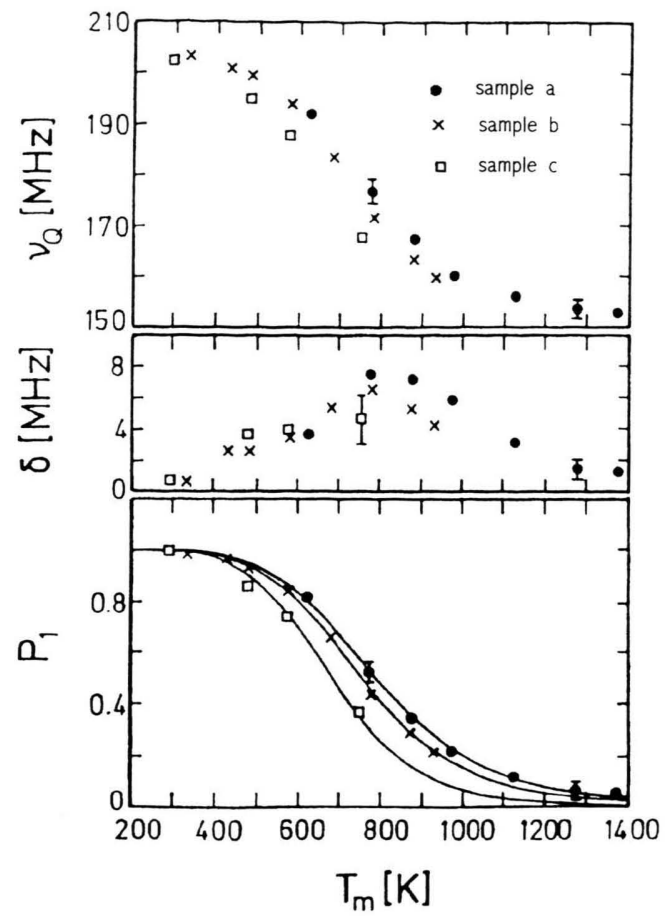

Fig. 11. Temperature dependent coupling constant $\nu_{\mathrm{Q}}$ (top), distribution width $\delta$ (middle) and equilibrium probability $\mathrm{P}_{1}$ in $\mathrm{Cr}_{2} \mathrm{O}_{3}$ [31]. $\mathrm{P}_{1}$ represents the probability to observe $\mathrm{EFG}_{1}$ in the two-state model of [12]. The data refer to three samples (a-c) implanted with different ${ }^{111}$ In-doses and then annealed at $1370 \mathrm{~K}$ in air.

change. In the bixbyite $\mathrm{Mn}_{2} \mathrm{O}_{3}$ all $\mathrm{Mn}$ ions have the charge +3 , but in the normal spinel $\mathrm{Mn}_{3} \mathrm{O}_{4}$ one third of the $\mathrm{Mn}$ ions have a charge of +2 , the rest remaining at +3 . Such changes occurring in the immediate neighborhood of the hyperfine probe will strongly affect the strength(s) of the EFG.

Even faster changes of the ion charges, possibly occurring many times within the observation time ( $\approx 200 \mathrm{~ns}$ ) of the hyperfine-sensitive probe, may be due to charge fluctuations, as already discussed in the case of magnetite (see Section 3). Such rapid changes will necessarily influence the PAC spectra and may introduce a dynamic hyperfine interaction. Neubauer et al. [30] found such charge fluctuations to occur in the wide-gap semiconductor $\mathrm{Cr}_{2} \mathrm{O}_{3}$. As it has corundum structure, like $\mathrm{Al}_{2} \mathrm{O}_{3}$ [33] and $\mathrm{Rh}_{2} \mathrm{O}_{3}$ [74], one expects a single equivalent cation site with axial symmetry $(\eta=0)$. However, after a moderate annealing at $973 \mathrm{~K}$, the experiments revealed two well defined EFGs, having the parameters $\nu_{\mathrm{Q} 1}=202(1) \mathrm{MHz}, \eta_{1}=0$ and $\nu_{\mathrm{Q} 2}=151(1) \mathrm{MHz}, \eta_{2}=0$. Both EFG tensors have 
the largest component $V_{z z}$ pointing along the [111] axis of the rhombohedral unit cell as expected for probes on substitutional sites. A longer annealing at $1370 \mathrm{~K}$ resulted in the observation of a single EFG having the average quadrupole frequency $\left\langle\nu_{\mathrm{Q}}\right\rangle$. It varied between the limits $\nu_{\mathrm{Q} 2}$ and $\nu_{\mathrm{Q} 1}$ and was reversible as function of the temperature (see the upper part of Figure 11). Strong variations of $\left\langle\nu_{\mathrm{Q}}\right\rangle$ coincided with large values of the frequency width $\delta$ describing the damping of the perturbation function (see middle part of Figure 11).

In the semiconductor $\mathrm{Cr}_{2} \mathrm{O}_{3}$ the dominant defect charge carriers in thermal equilibrium are electron holes [75]. If one assumes the trapping and release of holes at the $\mathrm{Cr}^{3+}$ ion next to a substitutional ${ }^{111} \mathrm{In}$ probe, all phenomena in the PAC experiment can be fully explained by the dynamical two-state model of Achtziger and Witthuhn [12]. The jump rates $\kappa_{2}$ (trapping, $\mathrm{Cr}^{3+} \rightarrow \mathrm{Cr}^{4+}$ ) and $\kappa_{1}\left(\right.$ release, $\mathrm{Cr}^{4+} \rightarrow \mathrm{Cr}^{3+}$ ) sensitively depend on the overall defect concentration, and the ratio of these two rates directly determines the average frequency $\left\langle\nu_{\mathrm{Q}}\right\rangle$ and damping $\delta$ of the PAC spectra [12]. Minor changes in the impurity concentratons already cause different transition temperatures from the defect-trapped to the defect-free configuration, as shown in Fig. 11 for differently implanted samples a-c. This microscopic picture of a charge fluctuation of a neighboring $\mathrm{Cr}$-ion could be backed by PCM calculations. Introducing a small relaxation of $0.29 \AA$ for the oversized ${ }^{111}$ In probe away from the $\mathrm{Cr}$-neighbor we are able to reproduce both EFGs in their direction and strengths $[31,8]$. The lower part of Fig. 11 gives the calculated temperature-dependence of the probability $P_{1}$ to feel $\mathrm{EFG}_{1}$. If these curves are interpreted in the framework of the ShockleyRead-statistics we find an activation energy of $E=$ $0.47(8) \mathrm{eV}$ which agrees with the activation energy for electron hole conductivity of $0.25-0.6 \mathrm{eV}$ (see Refs. in [31]).

It should be mentioned here that this special case of a dynamic hyperfine interaction is rarely observed, whereas other dynamic processes related to the ECdecay after-effects of ${ }^{111}$ In (see for an overview [76]) occur in quite a lot of oxides. Indeed, many PAC spectra of semiconducting or isolating oxides show a strong damping in the temperature range from 100 to $300 \mathrm{~K}$, which disappears reversibly at lower and higher temperatures. The reason for the non-static hyperfine interaction(s) are slow electron transport processes in the 100 ps to 100 ns time range, due to the lack of free electrons and/or their slow diffusivity in the lattice, necessary to re-install a stable electron configuration of the ${ }^{111} \mathrm{Cd}$ daugther atom. Proof of this explanation of the damping was obtained by control experiments with $\gamma$-decaying ${ }^{111 \mathrm{~m}} \mathrm{Cd}$ probes, implanted into the same samples at ISOLDE/CERN. Alternatively, by doping the oxide with electron donors, the missing electrons can be provided as was shown in the case of Ce-doped $\mathrm{La}_{2} \mathrm{O}_{3}[16,9,14]$. Different scenarios of dynamic processes have been developed by Lupascu and collaborators $[9,14]$ and also applied in the case of $\mathrm{La}_{2} \mathrm{O}_{3}$ [16] and $\mathrm{In}_{2} \mathrm{O}_{3}$ [15].

\section{Conclusions}

This survey has demonstrated that oxides offer a wide range of phase transitions to be studied with PAC. The ${ }^{111} \mathrm{In} /{ }^{111} \mathrm{Cd}$ impurity hyperfine probes in many cases can be positioned onto substitutional defect-free sites and can monitor magnetic, structural or chemical changes occurring in their immediate neighborhood. However, we have also indicated limitations of the technique, due to the different chemical nature of the mother (In) or daughter (Cd) impurity and the radioactive decay of ${ }^{111} \mathrm{In}$ to ${ }^{111} \mathrm{Cd}$.

\section{Acknowledgements}

The authors are very grateful to the many diploma and doctoral students who have been working for two decades on setting up the PAC instrumentation and carrying out the PAC experiments in oxides. In particular, we mention Roberta Attili, Axel Bartos, Wolfgang Bolse, Sönke Habenicht, Zbingiew Inglot, Jürgen Kesten, Doru Lupascu, Jens Luthin, Matthias Neubauer, Friedrich Raether, Nicole Reinecke, Johannes Roth, Helmut Schröder, Dirk Wegner, Thorsten Wenzel, Thomas Weber, and Dorothea Wiarda. We are also indebted to Detlev Purschke and Lüder Ziegeler for their constant, fruitful cooperation with the ${ }^{111}$ In ion implantations and sample annealings. The exchange of ideas with colleagues from Erlangen, Konstanz, Krakow, Leipzig and La Plata on the hyperfine interactions in oxides has been most welcome. This work is funded by the Deutsche Forschungsgemeinschaft. 
[1] J. M. Yeomans, Statistical Mechanics of Phase Transitions, Clarendon Press, Oxford 1992.

[2] C. Domb, and M. S. Green, eds., Phase Transitions and Critical Phenomena, Academic Press, London 197276, vols. 1-6; C. Domb, and J. L. Lebowitz, eds., Phase Transitions and Critical Phenomena, Academic Press, London 1983, vols. 7-.

[3] A. D. Bruce and R. A. Cowley, Structural Phase Transitions, Taylor and Francis, London 1981.

[4] G. Schatz, and A. Weidinger, in: Nuclear Solid Stae Physics, Wiley, New York 1996.

[5] W. Bolse, M. Uhrmacher, and K. P. Lieb, Phys. Rev. B36, 1818 (1987); W. Bolse, A. Bartos, J. Kesten, K. P. Lieb, and M. Uhrmacher, Ber. Bunsen-Ges. Phys. Chem. 93, 1285 (1989).

[6] K. P. Lieb, T. Weber, M. Uhrmacher, Z. Inglot, and A. Bartos, World-Scientific, Singapore 1991, p. 87.

[7] D. Wiarda, M. Uhrmacher, A. Bartos, and K. P. Lieb, J. Phys.: Cond. Matter 5, 4111 (1993).

[8] M. Uhrmacher, M. Neubauer, D. Lupascu, and K. P. Lieb, $25^{\text {th }}$ Anniversary of Hyperfine Interactions at La Plata, La Plata 1995, p. 82.

[9] D. Lupascu, M. Neubauer, Th. Wenzel, M. Uhrmacher, and K. P. Lieb, Nucl. Instr. Meth. B113, 507 (1996).

[10] K. P. Lieb, Contemp. Phys. 1999, in press.

[11] W. E. Evenson, J. A. Gardner, R. Wang, H.-T. Su, and A. G. McKale, Hyp. Int. 62, 283 (1990).

[12] N. Achtziger and W. Witthuhn, Phys. Rev. B47, 6990 (1993).

[13] R. Wang, J. A. Gardner, W. E. Evenson, and J. A. Sommers, Phys. Rev. B47, 638 (1993).

[14] D. Lupascu, M. Neubauer, S. Habenicht, Th. Wenzel, M. Uhrmacher, and K. P. Lieb, XXX Zakopane School of Physics, Condensed Matter Studies by Nuclear Methods, Eds. K. Tomala and E. A. Görlich, 1995 , p. 196.

[15] S. Habenicht, D. Lupascu, M. Uhrmacher, L. Ziegeler, K. P. Lieb, and the ISOLDE-Collaboration, Z. Phys. B101, 187 (1996).

[16] D. Lupascu, S. Habenicht, K. P. Lieb, M. Neubauer, M. Uhrmacher, and Th. Wenzel, Phys. Rev. B54, 871 (1996).

[17] Th. Wichert, N. Achtziger, H. Metzner, and R. Sielemann, in: Hyperfine Interactions of Defects in Semiconductors, ed. by G. Langouche, Elsevier, Amsterdam 1992, 77

[18] H. Frauenfelder, and R. M. Steffen, in K. Siegbahn, Alpha-, Beta- and Gamma Spectroscopy, North Holland, Amsterdam 1965.

[19] M. Uhrmacher, K. Pampus, F. J. Bergmeister, D. Purschke, and K. P. Lieb, Nucl. Instr. Meth. B9, 234 (1985).

[20] M. Uhrmacher, M. Neubauer, W. Bolse, L. Ziegeler, and K. P. Lieb, Nucl. Instr. Meth. B139, 306 (1998).

[21] A. Bartos, K. Schemmerling, Th. Wenzel, and M. Uhrmacher, Nucl. Instr. Meth. A330, 132 (1993).

[22] M. Uhrmacher, R.N. Attili, K. P. Lieb, K. Winzer, and M. Mekata, Phys. Rev. Lett. 76, 4829 (1996).
[23] J. Kajfosz, Inst. of Nuclear Physics (Cracow), Rep. No. 858/PM, 1973, unpublished.

[24] D. Wegner, Hyp. Int. 23, 179 (1985).

[25] Th. Wenzel, M. Uhrmacher, and K. P. Lieb, J. Phys. Chem. Solids 55, 683 (1994).

[26] F. Raether, D. Wiarda, K. P. Lieb, J. Chevallier, and G. Weyer, Z. Phys. B73, 467 (1989).

[27] A. Bartos, K. P. Lieb, A.F. Pasquevich, M. Uhrmacher and the ISOLDE-Collaboration, Phys. Lett. A157, 513 (1991).

[28] A. Bartos, K. P. Lieb, M. Uhrmacher, and D. Wiarda, Acta Cryst. B49, 165 (1993).

[29] D. Lupascu, J. Albohn, J. Shitu, A. Bartos, K. Krolas, M. Uhrmacher, and K. P. Lieb, Hyp. Int. 80, 959 (1993).

[30] D. Lupascu, A. Bartos, K. P. Lieb, and M. Uhrmacher, Z. Phys. B93, 448 (1994).

[31] M. Neubauer, A. Bartos, K. P. Lieb, D. Lupascu, M. Uhrmacher, and Th. Wenzel, Europhys. Lett. 29, 175 (1995)

[32] J. Luthin, K. P. Lieb, B. Lindgren, M. Neubauer, and M. Uhrmacher, Phys. Rev. B57, 15272 (1998).

[33] S. Habenicht, D. Lupascu, M. Neubauer, M. Uhrmacher, K. P. Lieb, and the ISOLDE-Collaboration, Hyp. Int. 120/121, 445 (1999).

[34] A. Bartos, M. Uhrmacher, L. Ziegeler, and K. P. Lieb, J. Alloys Comp. 179, 307 (1992).

[35] R. N. Attili, M. Uhrmacher, K. P. Lieb, L. Ziegeler, M. Mekata, and E. Schwarzmann, Phys. Rev. B53, 600 (1996).

[36] R. N. Attili, R. N. Saxena, A. W. Carbonari, J. Mestnik Filho, M. Uhrmacher, and K. P. Lieb, Phys. Rev. B58, 2563 (1998).

[37] M. Uhrmacher, V. V. Krishnamurthy, K. P. Lieb, A. Lopez-Garcia, and M. Neubauer, Z. Phys. Chem. 206, 249 (1998)

[38] P. de la Presa, R.E. Alonso, A. Ayala, S. Habenicht, V. V. Krishnamurthy, K. P. Lieb, A. López-Garcia, M. Neubauer, and M. Uhrmacher, J. All. Comp. 60, 749 (1999).

[39] P. de la Presa, K. P. Lieb, M. Uhrmacher, and L. Ziegeler, NQI-99, Leipzig 1999, in press.

[40] J. Roth, M. Uhrmacher, P. de la Presa, L. Ziegeler, and K. P. Lieb, NQI-99, Leipzig 1999, in press

[41] R. E. Vandenberghe, and E. de Grave, in Mössbauer Spectroscopy Applied to Inorganic Chemistry, Vol. 3, Plenum, New York 1989, p. 59.

[42] C. Hohenemser, T. Kachnowski, and T. K. Bergstresser, Phys. Rev. B13, 3154 (1976).

[43] Z. Inglot, D. Wegner, and K. P. Lieb, Hyp. Int. 50, 785 (1989).

[44] A. Bartos, W. Bolse, K. P. Lieb, and M. Uhrmacher, Phys. Lett. A130, 177 (1988).

[45] D. Wegner, Z. Inglot, and K. P. Lieb, Ber. Bunsen-Ges. Phys. Chem. 94, 1 (1990).

[46] D. Wegner, Z. Inglot, and K. P. Lieb, Hyp. Int. 59, 313 (1990); Z. Inglot, K. P. Lieb, M. Uhrmacher, T. Wenzel, and D. Wiarda, Z. Phys. B87, 323 (1992).

[47] Z. Inglot, D. Wiarda, K. P. Lieb, T. Wenzel, and M. Uhrmacher, J. Phys.: Cond. Matter 3, 4569 (1991); 
Z. Inglot, and D. Wegner, J. Phys.: Cond. Matter 3, 2137 (1991).

[48] D. Wiarda, A. Bartos, K. P. Lieb, M. Uhrmacher, and Th. Wenzel, XXVI Zakopane-School on Physics, J. Stanek, Ed., World Scientific, Singapore 1991, p. 340; D. Wiarda, T. Wenzel, M. Uhrmacher, and K. P. Lieb, J. Phys. Chem. Sol. 53, 1199 (1992).

[49] A. Bartos, M. Uhrmacher, K. P. Lieb, and W. Bolse, Hyp. Int. 50, 619 (1989); A. Bartos, D. Wiarda, Z. Inglot, K. P. Lieb, M. Uhrmacher, and T. Wenzel, Int. Journ. Mod. Phys. B7, 357 (1993).

[50] Th. Wenzel, M. Uhrmacher, and K. P. Lieb, Phil. Mag. A73, 1099 (1995).

[51] Z. Inglot, K. P. Lieb, M. Uhrmacher, T. Wenzel, and D. Wiarda, Hyp. Int. 120/121, 237 (1999).

[52] E. de Grave, R. M. Persoons, and R.E. Vandenberghe, in XXXII Zakopane School of Physics, A. Görlich, and K. Latka, Eds., Wydawnictwo Uniwersytetu Jagiell., Krakow 1997, p. 178.

[53] T. Riste and L. Tenzer, J. Phys. Chem. Solids 19, 117 (1961).

[54] K. Kubo and N. Ohata, J. Phys. Soc. Japan. 33, 21 (1972).

[55] R. A. Buckwald, and A. A. Hirsch, Solid State Comm. 17, 621 (1975).

[56] See Phil. Mag. 42, 337-452 (1980).

[57] M. Mekata, N. Yaguchi, T. Takagi, T. Sugino, S. Mitsuda, H. Yoshizawa, N. Hosoito, and T. Shinjo, J. Phys. Soc. Japan. 62, 4474 (1993).

[58] B. Reihl, J.G. Bednorz, K.A. Müller, Y. Juguet, G. Landgren, and J. F. Morar, Phys. Rev. B30, 803 (1984); Y. Tezuka, S. Shin, T. Ishii, T. Ijima, S. Suzuki, and S. Sato, J. Phys. Soc. Japan. 63, 347 (1994); Y. Haruyama, S. Kodaira, Y. Aiura, H. Brando, Y. Nishihara, T. Maruyama, Y. Sakisaka, and H. Kato, Phys. Rev. B53, 8032 (1996); D. J. Singh, Phys. Rev. B52, 12559 (1995); R. D. KingSmith and D. Vanderbuilt, Phys. Rev. B49, 5828 (1994).
[59] M. E. Lines, and A. M. Glass, in Principles and Applications of Ferroelectrics and Related Materials, Clarendon Press, Oxford 1977.

[60] G. Shirane, H. Danner, and R. Pepinsky, Phys. Rev. 105, 856 (1957).

[61] L. Aldon, M. Uhrmacher, C. Branci, L. Ziegeler, J. Roth, P. Schaaf, H. Metzner, J. Olivier-Fourcade, and J. C. Jumas, Phys. Rev. B58, 11303 (1998).

[62] M. Uhrmacher, L. Aldon, P. Schaaf, H. Metzner, J. Olivier-Fourcade, and J.-C. Jumas, Hyp. Int. 120/121, 371 (1999).

[63] P. Blaha, K. Schwarz, and P. H. Dederichs, Phys. Rev. B37, 2792 (1988).

[64] G. Frantz, R. Leiberich, and P. C. Schmidt, Z. Naturforsch. 47a, 182 (1992).

[65] F. D. Feiock and W. R. Johnson, Phys. Rev. 187, 39 (1969).

[66] A. Bartos, D. Wiarda, M. Uhrmacher, and K. P. Lieb, Hyp. Int. 80, 953 (1993).

[67] J. Shitu, D. Wiarda, T. Wenzel, M. Uhrmacher, K. P. Lieb, S. Bedi, and A. Bartos, Phys. Rev. B46, 7987 (1992).

[68] R.D. Shannon, Acta Cryst. A32, 751 (1976).

[69] V. V. Krishnamurthy, S. Habenicht, K. P. Lieb, M. Uhrmacher, and K. Winzer, Phys. Rev. B56, 355 (1997).

[70] R. Tetot and G. Boureau, Phys. Rev. B40, 2311 (1989).

[71] Th. Wenzel, A. Bartos, M. Uhrmacher, D. Wiarda, and K. P. Lieb, Ann. Physik 1, 155 (1992).

[72] Th. Wenzel, F. Lange, K. P. Lieb, M. Martin, H. Schmalzried, M. Uhrmacher, and L. Ziegeler, Hyp. Int. 120/121, 439 (1999).

[73] D. Wiarda, Doctoral thesis, Göttingen (1992), unpublished.

[74] J. Kesten, W. Bolse, K. P. Lieb, and M. Uhrmacher, Hyp. Int. 60, 683 (1990).

[75] P. Kofstad, in: Non-stoichiometry, Diffusion and Electrical Conductivity in Binary Metal Oxides, WileyInterscience, New York 1972.

[76] M. Deicher, Hyp. Int. 79, 681 (1993). 